\title{
A novel PDGFRB sequence variant in a family with a mild form of primary familial brain calcification: a case report and a review of the literature
}

\author{
Stine Westergaard Mathorne ${ }^{1}$, Kristina Sørensen ${ }^{1}$, Christina Fagerberg ${ }^{1}$, Matthias Bode ${ }^{2}$ and
} Jens Michael Hertz ${ }^{1,3^{*}}$

\begin{abstract}
Background: Primary familial brain calcification is a rare autosomal dominant or recessive neurodegenerative disease, characterized by bilateral brain calcifications in different areas of the brain. It is a clinically heterogeneous disease and patients are reported to exhibit a wide spectrum of neurological and psychiatric symptoms. Mutations in five genes have been identified so far including SLC2OA2, PDGFRB, PDGFB, XPR1, and MYORG. PDGFRB encodes the platelet-derived growth factor receptor-beta, and is expressed in neurons, vascular smooth muscle cells and pericytes. Patients with a PDGFRB mutation seem to exhibit a milder phenotype and milder brain calcification on brain imaging than patients with SLC2OA2 and PDGFB mutations. However, this is based on a few observations so far.

Case presentation: We present a Danish family with bilateral brain calcifications and mild clinical symptoms of primary familial brain calcification, segregating with a novel PDGFRB sequence variant: c.1834G > A; p.(Gly612Arg), detected by whole exome sequencing. The variant results in physiochemical changes at the amino acid level, and affects a highly conserved nucleotide as well as amino acid. It is located in the tyrosine kinase domain of PDGFRß. Segregation analysis and in silico analyses predicted the missense variant to be disease causing.

Conclusion: Our study confirms that PDGFRB mutation carriers in general have a mild clinical phenotype, and basal ganglia calcifications can be detected by a CT scan, also in asymptomatic mutation carriers.
\end{abstract}

Keywords: PDGFRB, Fahr syndrome, Primary familial brain calcification

\section{Background}

Primary familial brain calcification (PFBC) is a rare progressive neurodegenerative disease, previously known as Fahr's disease or idiopathic basal ganglia calcification. It is inherited in an autosomal dominant as well as an autosomal recessive manner, and is characterized by bilateral calcifications in the basal ganglia and other brain regions including the cerebellum, thalamus and the brain stem [1]. Brain calcification is a common finding in older people $[2,3]$ and can be a secondary manifestation of

\footnotetext{
* Correspondence: jens.michael.hertz@rsyd.dk

'Department of Clinical Genetics, Odense University Hospital, J. B. Winsløvs Vej 4, DK-5000 Odense, Denmark

${ }^{3}$ Department of Clinical Research, University of Southern Denmark, Odense, Denmark

Full list of author information is available at the end of the article
}

different diseases [4]. However, the calcification in PFBC is more severe than what is expected during normal aging.

PFBC is a clinically heterogeneous disease. Patients are reported to exhibit a wide spectrum of neurological and/ or psychiatric symptoms. Most frequent symptoms seem to be movement disorders, psychiatric symptoms, and cognitive impairment, although some affected individuals remain asymptomatic $[1,5]$.

Approximately, no more than one fourth of individuals with a clinical diagnosis of PFBC are found to have a heterozygous pathogenic variant in one of the four genes known to cause autosomal dominant PFBC: SLC20A2, PDGFRB, PDGFB and XPR1, and some may have mutations in the MYORG gene related to autosomal recessive PFBC [6].

(c) The Author(s). 2019 Open Access This article is distributed under the terms of the Creative Commons Attribution 4.0 International License (http://creativecommons.org/licenses/by/4.0/), which permits unrestricted use, distribution, and 
PDGFRB is located at $5 \mathrm{q} 32$ and encodes the receptor for platelet-derived growth factor beta (PDGF-B). PDGFR $\beta$ (Platelet-Derived Growth Factor Receptor Beta) is expressed in neurons, vascular smooth muscle cells and pericytes [7-9]. There seems to be a tendency of a mild phenotype and a high proportion of asymptomatic individuals in patients with $P D G F R B$ variants compared to patients with $S L C 2 O A 2$ and $P D G F B$ variants $[1,5]$.

Ten different sequence variants in PDGFRB in patients with PFBC have been reported so far [10]. A number of other phenotypes have been associated with sequence variants in PDGFRB including infantile myofibromatosis and Kosaki overgrowth syndrome [11-13].

We detected a novel PDGFRB missense variant by exome sequencing in a Danish family with bilateral brain calcifications and mild clinical symptoms of PFBC. Segregation analysis of the family could demonstrate that basal ganglia calcifications can be detected by a CT scan, also in asymptomatic mutation carriers.

\section{Case presentation}

The proband (III:1) is a 58-year-old woman with paresthesia and tendency to muscle cramps in the lower legs and feet.

She was referred to a neurologist at the age of 56 because of a sensation of warmth/cold in the lower legs and tendency to cramp in the lower legs, especially the feet. Neurological examination was normal. She was born with atrial septal defect (ASD), has had rheumatoid arthritis since the age of 28 years, has hypercholesterolemia, and recently she was diagnosed with anxiety.

MRI of the brain showed bilateral calcifications in the globus pallidus, putamen, thalamus and nucleus dentatus, as well as diffuse white matter lesions in both cerebral hemispheres consistent with chronic ischemia (leukoaraiosis). Cerebral computerized tomography (CT) scan also showed bilateral calcifications in the basal ganglia and cerebellum, and distinct periventricular leukoaraiosis.

The probands mother (II:2), have paroxysmal atrial fibrillation, and was admitted to hospital at the age of 74 years suspected of having transient ischemic attack. She presented with sudden blindness on both eyes and dizziness, lasting for about 3-4 min. Neurological examination showed decreased vibratory sensation, and the Achilles reflexes was absent bilateral. MRI of the brain showed distinct leukoaraiosis due to ischemic demyelination. CT scan was not performed.

The monozygotic twin sister of the proband (III:2) was admitted to hospital at the age of 49 years because of paresthesia on the left side. Since her mid-fifties she has had sore muscles in all four extremities. At the time of diagnosis, she suffered from restless legs syndrome with an urge to move the legs, unpleasant sensations in her legs and sometimes in the hands as well, totally relieved by the movement. Neurological examination was normal except slight insecurity at Rombergs test. A CT scan showed bilateral calcifications in the basal ganglia and cerebellum, extensive periventricular leukoaraiosis. Magnetic resonance imaging (MRI) showed white matter lesions in both cerebral hemispheres and the brain stem. She was also born with ASD. The two monozygotic twin sisters are concordant with respect to the age of onset.

A younger sister (III:3), who suffers from epilepsy, was admitted to hospital at the age of 48 years because of transient dizziness and hemiparesis at the right side. Both CT scan and brain MRI showed bilateral calcifications in the basal ganglia and cerebellar areas, as well as distinct leukoaraiosis.

The probands youngest sister (III:4) is clinically asymptomatic. Nevertheless, she has bilateral calcifications in the basal ganglia and in the nucleus dentatus on her CT scan (Table 1, Fig. 1).

DNA from the proband and her mother was extracted from EDTA-stabilized peripheral blood lymphocytes and subjected to exome capture using NimbleGen SeqCap EZ MedExome (Roche), followed by sequencing on an Illumina NextSeq550 platform to a mean coverage of $140 x$, with $95 \%$ of targeted bases covered with minimum 30x coverage. Raw reads were aligned using the Burrows-Wheeler Alignment tool v. 0.7.15 [14] and the GATK (Genome Analysis Toolkit) Best Practice pipeline v. 3.8-0 was used for variant calling [15]. Annotation and filtering of variants was performed using VarSeq 2.0.2 (Golden Helix). The sequence variant has been confirmed by bidirectional Sanger sequencing of PDGFRB (NM_002609.3) according to standard procedures.

Whole exome sequencing on DNA from the proband and her mother, and bidirectional Sanger sequencing of PDGFRB in III:2, III:3 and III:4, showed heterozygosity for a novel sequence variant, c.1834G $>$ A; p.(Gly612Arg) in PDGFRB. The sequence variant is located in exon 13 within the tyrosine kinase domain [Table 2], and can be classified as likely pathogenic class 4 variant according to the American College of Medical Genetics and Genomics and the Association for Molecular Pathology [16]. A CADD score of 29.5 further support the pathogenicity of the variant [17].

The clinical findings in the present family are compatible with the phenotype associated with variants in PDGFRB (Fig. 1, Table 1).

\section{Discussion and conclusion}

We present a family with mild clinical signs of PFBC, in which a not previously reported heterozygous sequence variant in $P D G F R B$ was found to segregate. The variant, c.1834G>A; p.(Gly612Arg), is located in exon 13 and 
Table 1 Clinical features and imaging findings of family members heterozygous for the PDGFRB sequence variant

\begin{tabular}{|c|c|c|c|c|c|}
\hline Patient & $\begin{array}{l}\text { Age at onset of clinical } \\
\text { symptoms, years }\end{array}$ & $\begin{array}{l}\text { Age at } \\
\text { evaluation, years }\end{array}$ & Clinical features & CT scan & MRI \\
\hline$\|: 2$ & NA & 74 & $\begin{array}{l}\text { TIA } \\
\text { Atrial fibrillation } \\
\text { Decreased } \\
\text { vibratory sensation }\end{array}$ & ND & Leukoaraiosis \\
\hline III:1 & 54 & 56 & $\begin{array}{l}\text { Anxiety } \\
\text { Paresthesia } \\
\text { Tendency to } \\
\text { cramp in feet. } \\
\text { Congenital ASD }\end{array}$ & $\begin{array}{l}\text { Basal ganglia, cerebellum, distinct } \\
\text { periventricular leukoaraiosis. }\end{array}$ & $\begin{array}{l}\text { Pa, Pu, T, D } \\
\text { Diffuse white matter lesions at temporal } \\
\text { horns, corona radiata, centrum semiovale, } \\
\text { subcortical and periventricular consistent } \\
\text { with chronic ischemia }\end{array}$ \\
\hline |II:2 & 49 & 56 & $\begin{array}{l}\text { Paresthesia } \\
\text { Sore muscles } \\
\text { Congenital ASD }\end{array}$ & $\begin{array}{l}\text { Basal ganglia, cerebellum, distinct } \\
\text { leukoaraiosis }\end{array}$ & $\begin{array}{l}\text { WM lesions in both cerebral hemispheres } \\
\text { and brain stem }\end{array}$ \\
\hline |ll:3 & 48 & 48 & $\begin{array}{l}\text { Epilepsy } \\
\text { Transient dizziness } \\
\text { and hemiparesis }\end{array}$ & Basal ganglia and cerebellar areas & ND \\
\hline |ll:4 & & 52 & None & Ca, lentiformis, D & ND \\
\hline
\end{tabular}

Abbreviations: $N A=$ not applicable, $N D=$ not done, $C a=$ caudate calcifications, $D=$ dentate calcifications, $P a=$ globus pallidus calcifications, $P u=$ putamen calcifications, $T=$ thalamic calcifications; $T I A=$ transient ischemic attack

All calcifications mentioned in the table are bilateral

results in a glycine being substituted by an arginine in the tyrosine kinase domain of PDGFR $\beta$. Glycine at amino acid position 612 in PDGFR $\beta$ is evolutionary conserved to Fruit fly (Fig. 2). Conversion to arginine results in a physiochemical change, and is predicted to be disease causing by the in silico program MutationTaster [18], deleterious by SIFT [19] and probably damaging by
PolyPhen-2 [20]. It is most likely that heterozygosity for this variant explains the phenotype of the affected family members, who presented with a mild clinical phenotype of PFBC, but widespread calcifications on a CT-scan.

PDGFR $\beta$ is a cell-surface tyrosine kinase receptor. It consists of an intracellular tyrosine-kinase domain and five extracellular immunoglobulin loops [21]. Activation

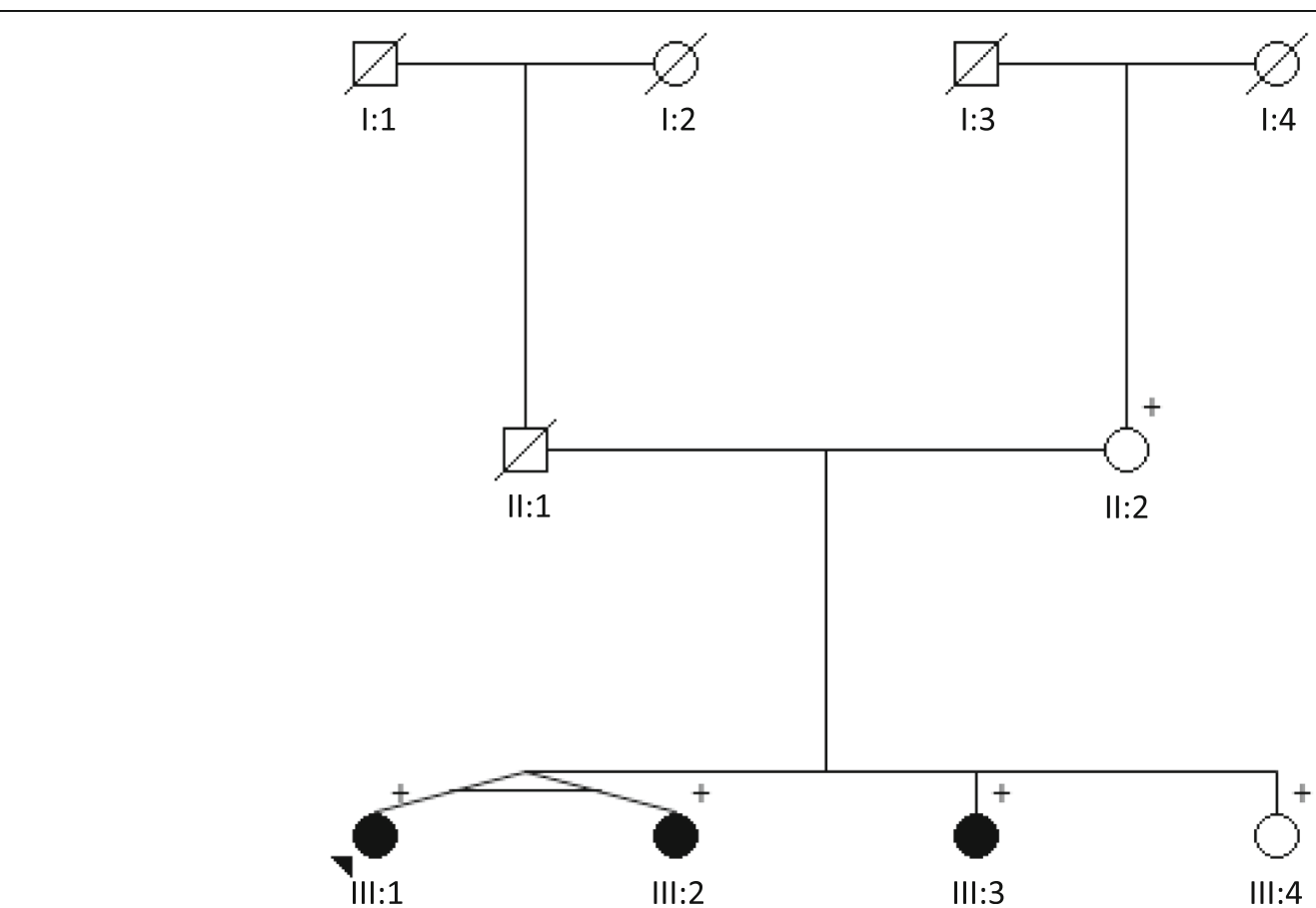

Fig. 1 Pedigree of the family. The proband is marked with an arrow, filled symbols indicate individuals with brain calcification on $C T,+$ indicate mutation carriers 
Table 2 Variants reported in PDGFRB and associated with PFBC

\begin{tabular}{|c|c|c|c|c|c|}
\hline $\begin{array}{l}\text { Nucleotide substitution } \\
\text { (Ref.) }\end{array}$ & $\begin{array}{l}\text { Amino acid } \\
\text { substitution }\end{array}$ & Exon & Domain affected & $\begin{array}{l}\text { Global allele frequency } \\
\text { (gnomAD) }\end{array}$ & In silico analysis \\
\hline c.3G>A [30] & p.(Met1lle) & 2 & Initiation codon & No data & $\begin{array}{l}\text { SIFT: damaging } \\
\text { MutationTaster: polymorphism } \\
\text { PolyPhen-2: benign }\end{array}$ \\
\hline c.676C>T [31] & p.(Arg226Cys) & 5 & $\begin{array}{l}\text { Extracellular, lg-like C2-type } \\
3\end{array}$ & No data & $\begin{array}{l}\text { SIFT: deleterious } \\
\text { MutationTaster: disease causing } \\
\text { PolyPhen-2: probably } \\
\text { damaging }\end{array}$ \\
\hline c.1126C>T [32] & p.(Arg376Trp) & 7 & $\begin{array}{l}\text { Extracellular, lg-like C2-type } \\
4\end{array}$ & $0.00000829 / 2$ & $\begin{array}{l}\text { SIFT: deleterious } \\
\text { MutationTaster: disease causing } \\
\text { PolyPhen2: probably damaging }\end{array}$ \\
\hline c.1787C>T [31] & p.(Pro596Leu) & 12 & Tyrosine kinase domain & $0.00080 / 2$ & $\begin{array}{l}\text { SIFT: deleterious } \\
\text { MutationTaster: disease causing } \\
\text { PolyPhen-2: probably } \\
\text { damaging }\end{array}$ \\
\hline c. $1834 G>A(*)$ & p.(Gly612Arg) & 13 & Tyrosine kinase domain & No Data & $\begin{array}{l}\text { SIFT: deleterious } \\
\text { MutationTaster: disease causing } \\
\text { PolyPhen-2: probably } \\
\text { damaging }\end{array}$ \\
\hline c.1973 T>C [27] & p.(Leu658Pro) & 14 & Tyrosine kinase domain & No data & $\begin{array}{l}\text { SIFT: deleterious } \\
\text { MutationTaster: disease causing } \\
\text { PolyPhen-2: probably } \\
\text { damaging }\end{array}$ \\
\hline c.2083C>T [22] & p.(Arg695Cys) & 15 & Tyrosine kinase domain & $0.000110 / 27$ & $\begin{array}{l}\text { SIFT: deleterious } \\
\text { MutationTaster: disease causing } \\
\text { PolyPhen-2: probably } \\
\text { damaging }\end{array}$ \\
\hline c.2209G>A [30] & p.(Asp737Asn) & 16 & Tyrosine kinase domain & $0.00000406 / 1$ & $\begin{array}{l}\text { SIFT: Tolerated } \\
\text { MutationTaster: disease causing } \\
\text { PolyPhen-2: probably } \\
\text { damaging }\end{array}$ \\
\hline c.2531A>G [31] & p.(Asp844Gly) & 18 & Tyrosine kinase domain & No data & $\begin{array}{l}\text { SIFT: deleterious } \\
\text { MutationTaster: disease causing } \\
\text { PolyPhen-2: probably } \\
\text { damaging }\end{array}$ \\
\hline c.2959C>T [27] & p.(Arg987Trp) & 22 & - & $0.0000285 / 7$ & $\begin{array}{l}\text { SIFT: deleterious } \\
\text { MutationTaster: disease causing } \\
\text { PolyPhen-2: probably } \\
\text { damaging }\end{array}$ \\
\hline c.3212A>T [5] & p.(Glu1071Val) & 23 & - & No data & $\begin{array}{l}\text { SIFT: Tolerated } \\
\text { MutationTaster: disease causing } \\
\text { PolyPhen-2: possibly damaging }\end{array}$ \\
\hline
\end{tabular}

Detected in the present study

of PDGFR $\beta$ results in dimerization of the receptor and autophosphorylation of tyrosine residues. This further activates downstream signaling pathways which mediates cellular proliferation, differentiation, survival, and migration [21].

The intracellular protein tyrosine kinase domain mediates the intrinsic functions of the activated PDGFR $\beta$ receptor, thus altered phosphorylation at the tyrosine kinase domain may induce impaired signaling in the PDGF-B/PDGFR $\beta$ pathway. A functional study concluded that missense variants in the tyrosine kinase domain of PDGFR $\beta$ directly interfere with autophosphorylation of the PDGFR $\beta$ receptor [22]. Furthermore, several studies have shown that in patients with PFBC,
PDGFB and PDGFRB variants lead to decreased PDGF-B/PDGFR $\beta$ signaling [22-24]. In contrast, increased signaling is associated with cancers, infantile myofibromatosis, Kosaki overgrowth syndrome and Penttinen syndrome [11-13, 25, 26].

The amino acid substitution, p.(Gly612Arg), as detected in all family members with CT scans in accordance with a diagnosis of PFBC in the present family, is located in the intracellular tyrosine kinase domain, and is predicted to impair the PDGF-B/PDGFR $\beta$ pathway.

Two pathophysiological hypotheses for the molecular mechanism of PFBC caused by PDGFRB mutations have been suggested. Loss of function of PDGFRB could induce calcium depositions in the brain, by impairing 


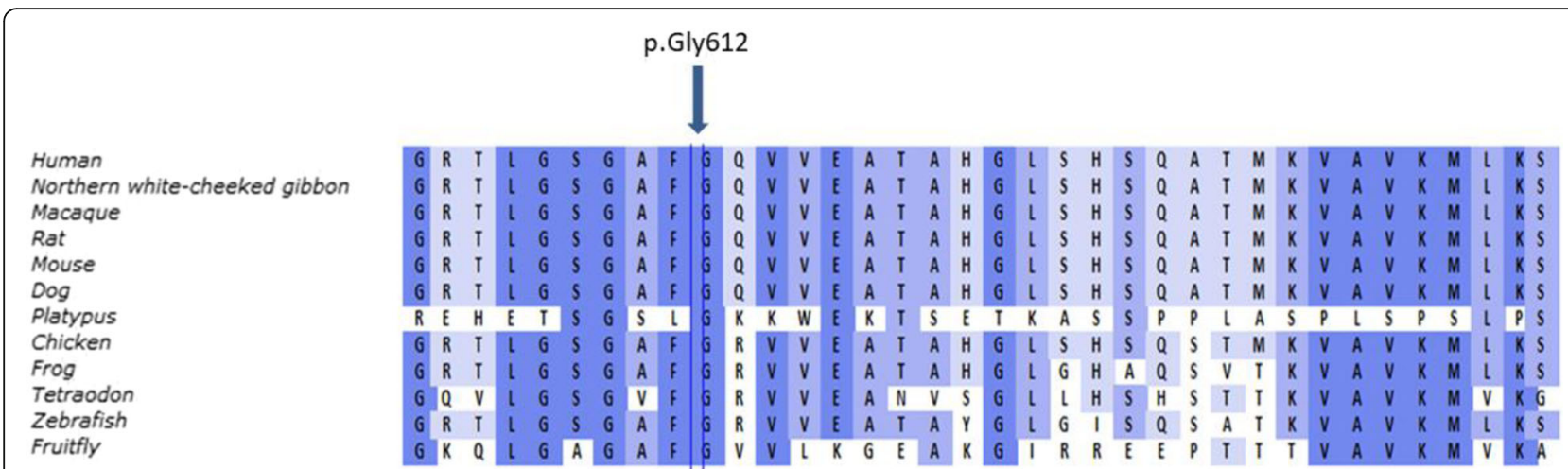

Fig. 2 Evolutionary alignments of the affected amino acid in PDGFRB. Amino acids conserved relative to the human sequence are shaded in blue

the integrity of the blood-brain barrier. This hypothesis might be supported by the functional studies, who found that PDGFRB variants and PDGFB variants associated with $\mathrm{PFBC}$ results in loss/reduced function of the gene product [22-24]. Another hypothesis suggests that an activating mutation could induce brain calcifications directly through influence of the PDGF-Pit-1 pathway [27]. Although different hypotheses have been suggested, it is not yet clear how impaired PDGF-B/ PDGFR $\beta$ signaling leads to microvascular calcification in the brain $[24,27]$.

In patients with $\mathrm{PFBC}$, expressivity is highly variable in symptoms, age of onset (median 31 years, range 6-77 years) [28] and severity of symptoms, even within the same family. A systematic review by Tadic et al., showed that the penetrance of the imaging phenotype is $100 \%$, however the penetrance of the clinical phenotype is reduced to $61 \%$ [1]. Especially patients with a PDGFRB mutation seem to exhibit a mild clinical phenotype and have the highest proportion of asymptomatic individuals [1]. This is consistent with the findings in the present study, where family members with the sequence variant presented with a mild clinical phenotype of PFBC with few or no neurological symptoms, but all who were evaluated with a CT scan presented with calcifications on brain imaging (Table 1).

According to Nicolas et al., no correlation is found between location of calcification and symptoms, nor between the extent of calcification and the severity of symptoms [5]. However, it has been observed that the severity of calcifications is higher in symptomatic versus asymptomatic people $[5,29]$. Furthermore, it has been reported that PDGFRB mutation carriers seem to have a milder brain calcification [28].

In conclusion, we report a novel heterozygous missense variant, c.1834G>A; p.(Gly612Arg) in PDGFRB in a family with a mild form of PFBC. Our study confirms that PDGFRB mutation carriers in general may have a mild clinical phenotype, and basal ganglia calcifications can be detected by a CT scan also in asymptomatic mutation carriers.

\section{Abbreviations}

CADD: Combined Annotation-Dependent Depletion; CT: Computerized tomography; DNA: Deoxyribonucleic acid; EDTA: Ethylenediaminetetraacetic acid; GATK: Genome Analysis Toolkit (variant calling software); HGMD: Human Genome Mutation Database; MRI: Magnetic resonance imaging; PDGF-B: Platelet-derived growth factor beta (gene/protein name); PDGFRß: Platelet-derived growth factor receptor beta (gene/protein name); PFBC: Primary familial brain calcification; SIFT: Sorting Intolerant From Tolerant (name of a prediction software); SLC20A2: Solute Carrier Family 20, member 2 (gene/protein name); XPR1: Xenotropic and Polytropic Retrovirus Receptor (gene/protein name)

\section{Acknowledgements}

No acknowledgements.

\section{Funding}

No funding has been obtained.

\section{Availability of data and materials}

The dataset analysed are available from the corresponding author on reasonable request.

\section{Authors' contributions}

SWM and JMH wrote the case report. CF and KS performed the exome sequencing. $\mathrm{MB}$ contributed with clinical information of the proband. All authors read and approved the final manuscript.

\section{Ethics approval and consent to participate}

The local ethics committee ruled that no formal ethics approval was required in this case (The Regional Committees on Health Research Ethics for Southern Denmark). Written informed consent for clinical examination and testing has been obtained from all individuals in the family.

\section{Consent for publication}

Written informed consent was obtained from the proband and the proband's family for publication.

\section{Competing interests}

The authors declare that they have no competing interests.

\section{Publisher's Note}

Springer Nature remains neutral with regard to jurisdictional claims in published maps and institutional affiliations. 


\section{Author details}

'Department of Clinical Genetics, Odense University Hospital, J. B. Winsløvs Vej 4, DK-5000 Odense, Denmark. ${ }^{2}$ Department of Neurology, Odense University Hospital, Odense, Denmark. ${ }^{3}$ Department of Clinical Research, University of Southern Denmark, Odense, Denmark.

Received: 24 January 2019 Accepted: 31 March 2019

Published online: 12 April 2019

\section{References}

1. Tadic V, Westenberger A, Domingo A, Alvarez-Fischer D, Klein C, Kasten M. Primary familial brain calcification with known gene mutations: a systematic review and challenges of phenotypic characterization. JAMA Neurology. 2015;72(4):460-7

2. Simoni M, Pantoni L, Pracucci G, Palmertz B, Guo X, Gustafson D, et al. Prevalence of $C T$-detected cerebral abnormalities in an elderly Swedish population sample. Acta Neurol Scand. 2008;118(4):260-7.

3. Yamada M, Asano T, Okamoto K, Hayashi Y, Kanematsu M, Hoshi H, et al High frequency of calcification in basal ganglia on brain computed tomography images in Japanese older adults. Geriatr Gerontol Int. 2013;13(3):706-10

4. Westenberger A, Klein C. The genetics of primary familial brain calcifications Curr Neurol Neurosci Rep. 2014;14(10):490

5. Nicolas G, Pottier C, Charbonnier C, Guyant-Maréchal L, Le Ber I, Pariente J, et al. Phenotypic spectrum of probable and genetically-confirmed idiopathic basal ganglia calcification. Brain. 2013:136(11):3395-407.

6. Yao X-P, Cheng X, Wang C, Zhao M, Guo X-X, Su H-Z, et al. Biallelic mutations in MYORG cause autosomal recessive primary familial brain calcification. Neuron. 2018;98(6):1116-23.

7. Lindahl P, Johansson BR, Levéen P, Betsholtz C. Pericyte loss and microaneurysm formation in PDGF-B-deficient mice. Science. 1997; 277(5323):242-5.

8. Ishii Y, Oya T, Zheng L, Gao Z, Kawaguchi M, Sabit H, et al. Mouse brains deficient in neuronal PDGF receptor- $\beta$ develop normally but are vulnerable to injury. J Neurochem. 2006:98(2):588-600.

9. Hutchins JB, Jefferson VE. Developmental distribution of platelet-derived growth factor in the mouse central nervous system. Dev Brain Res. 1992;67(2):121-35.

10. Stenson PD, Mort M, Ball EV, Evans K, Hayden M, Heywood S, et al. The human gene mutation database: towards a comprehensive repository of inherited mutation data for medical research, genetic diagnosis and next-generation sequencing studies. Hum Genet. 2017;136(6):665-77.

11. Martignetti John A, Tian L, Li D, Ramirez MCM, Camacho-Vanegas O, Camacho SC, et al. Mutations in PDGFRB cause autosomal-dominant infantile Myofibromatosis. Am J Hum Genet. 2013;92(6):1001-7.

12. Cheung Yee $H$, Gayden T, Campeau Philippe M, LeDuc CA, Russo D Nguyen $\mathrm{V}$ - $\mathrm{H}$, et al. A recurrent PDGFRB mutation causes familial infantile Myofibromatosis. Am J Hum Genet. 2013;92(6):996-1000.

13. Takenouchi T, Yamaguchi Y, Tanikawa A, Kosaki R, Okano H, Kosaki K. Novel overgrowth syndrome phenotype due to recurrent de novo PDGFRB mutation. J Pediatr. 2015;166(2):483-6.

14. Li H. Aligning sequence reads, clone sequences and assembly contains with BWA-MEM: Oxford University Press; 2014. p. 1-3. Available from: http://arxiv. org/abs/1303.3997

15. Van der Auwera GA, Carneiro MO, Hartl C, Poplin R, Del Angel G, LevyMoonshine A, et al. From FastQ data to high confidence variant calls: the Genome Analysis Toolkit best practices pipeline. Curr Protoc Bioinformatics. 2013;43(1110):11.0.1-0.33

16. Richards S, Aziz N, Bale S, Bick D, Das S, Gastier-Foster J. Standards and guidelines for the interpretation of sequence variants: a joint consensus recommendation of the American College of Medical Genetics and Genomics and the Association for Molecular Pathology. Genetics in Medicine. 2015;17(5):405-24.

17. Rentzsch P, Witten D, Cooper GM, Shendure J, Kircher M. CADD: predicting the deleteriousness of variants throughout the human genome. Nucleic Acids Res. 2019;47:D886-94.

18. Schwarz JM, Rödelsperger C, Schuelke M, Seelow D. MutationTaster evaluates disease-causing potential of sequence alterations. Nat Methods. 2010;7:575.

19. Ng PC, Henikoff S. SIFT: predicting amino acid changes that affect protein function. Nucleic Acids Res. 2003;31(13):3812-4.
20. Adzhubei IA, Schmidt S, Peshkin L, Ramensky VE, Gerasimova A, Bork P, et al. A method and server for predicting damaging missense mutations. Nat Methods. 2010;7:248

21. Andrae J, Gallini R, Betsholtz C. Role of platelet-derived growth factors in physiology and medicine. Genes Dev. 2008;22(10):1276-312.

22. Sanchez-Contreras M, Baker MC, Finch NA, Nicholson A, Wojtas A, Wszolek ZK, et al. Genetic screening and functional characterization of PDGFRB mutations associated with basal ganglia calcification of unknown etiology. Hum Mutat. 2014;35(8):964-71.

23. Arts FA, Velghe Al, Stevens M, Renauld JC, Essaghir A, Demoulin JB. Idiopathic basal ganglia calcification-associated PDGFRB mutations impair the receptor signalling. J Cell Mol Med. 2015;19(1):239-48.

24. Vanlandewijck M, Lebouvier T, Andaloussi Mäe M, Nahar K, Hornemann S, Kenkel D, et al. Functional Characterization of Germline Mutations in PDGFB and PDGFRB in Primary Familial Brain Calcification. PloS one. 2015;10(11):e0143407-e.

25. Appiah-Kubi K, Lan T, Wang Y, Qian H, Wu M, Yao X, et al. Platelet-derived growth factor receptors (PDGFRs) fusion genes involvement in hematological malignancies. Crit Rev Oncol Hematol. 2016;109:20-34.

26. Johnston Jennifer J, Sanchez-Contreras Monica Y, Keppler-Noreuil Kim M, Sapp J, Crenshaw M, Finch NiCole A, et al. A point mutation in PDGFRB causes autosomal-dominant Penttinen syndrome. Am J Hum Genet. 2015;97(3):465-74

27. Nicolas G, Pottier C, Maltête D, Coutant S, Rovelet-Lecrux A, Legallic S, et al. Mutation of the PDGFRB gene as a cause of idiopathic basal ganglia calcification. Neurology. 2013:80(2):181.

28. Nicolas G, Charbonnier C, de Lemos RR, Richard AC, Guillin O, Wallon D, et al. Brain calcification process and phenotypes according to age and sex: Lessons from SLC20A2, PDGFB, and PDGFRB mutation carriers. Am J Med Genet B Neuropsychiatr Genet. 2015;168(7):586-94.

29. Manyam BV. What is and what is not 'Fahr's disease'. Parkinsonism and Related Disorders. 2005;11(2):73-80.

30. Wang C, Yao X-P, Chen H-T, Lai J-H, Guo X-X, Su H-Z, et al. Novel mutations of PDGFRB cause primary familial brain calcification in Chinese families. J Hum Genet. 2017:62:697.

31. Ramos EM, Carecchio M, Lemos R, Ferreira J, Legati A, Sears RL, et al. Primary brain calcification: an international study reporting novel variants and associated phenotypes. Eur J Hum Genet. 2018;26:1462-77.

32. DeMeo NN, Burgess JD, Blackburn PR, Gass JM, Richter J, Atwal HK, et al. Cooccurrence of a novel PDGFRB variant and likely pathogenic variant in CASR in an individual with extensive intracranial calcifications and hypocalcaemia. Clinical Case Reports. 2017;6(1):8-13.

Ready to submit your research? Choose BMC and benefit from:

- fast, convenient online submission

- thorough peer review by experienced researchers in your field

- rapid publication on acceptance

- support for research data, including large and complex data types

- gold Open Access which fosters wider collaboration and increased citations

- maximum visibility for your research: over $100 \mathrm{M}$ website views per year

At $\mathrm{BMC}$, research is always in progress.

Learn more biomedcentral.com/submission 